\title{
Downstream hydraulic geometry of alluvial rivers
}

\author{
PIERRE Y. JULIEN
}

Department of Civil and Environmental Engineering, Colorado State University, Fort Collins, Colorado 80523, USA pierre@engr.colostate.edu

\begin{abstract}
This article presents a three-level approach to the analysis of downstream hydraulic geometry. First, empirical concepts based on field observations of 'poised' conditions in irrigation canals are examined. Second, theoretical developments have been made possible by combining basic relationships for the description of flow and sediment transport in alluvial rivers. Third, a relatively new concept of equivalent channel widths is presented. The assumption of equilibrium may describe a perpetual state of change and adjustments. The new concepts define the trade-offs between some hydraulic geometry parameters such as width and slope. The adjustment of river widths and slope typically follows a decreasing exponential function and recent developments indicate how the adjustment time scale can be quantified. Some examples are also presented to illustrate the new concepts presented and the realm of complex river systems.
\end{abstract}

Key words alluvial channels; downstream hydraulic geometry; river morphology

\section{INTRODUCTION}

Rivers have been a source of life since ancestral times. The ability of rivers to convey water in the downstream direction is known to all. However, this is only half the story since rivers also have the capability to transport large volumes of sediment. When the morphology of rivers is dictated by rock outcrop and non-erodible surfaces, bed-rock control and the rigid boundary of rivers makes them static. However, the dynamic capabilities of rivers are brought to life in transporting and managing large volumes of sediment. As flood waves attenuate in the downstream direction, the transport capacity of rivers gradually decreases and rivers shape their own morphology. Rivers flowing in their own alluvium are called alluvial rivers. One of the most interesting properties of alluvial rivers is the ability to deform their own boundary to migrate laterally and also change their longitudinal profiles.

The morphology of alluvial rivers has led to a dual description of hydraulic geometry: (1) ata-station hydraulic geometry, and (2) downstream hydraulic geometry. The at-a-station hydraulic geometry defines the relationship between river width, depth, velocity and slope as a function of discharge at a fixed cross-section. For a fixed location, we investigate how the river looks under mean flow conditions as compared to during floods and droughts. Since floodwaters spread out over the floodplains, the geometry of rivers during floods cannot really be described as a function of discharge. The description of bankfull hydraulic geometry of a river gives perhaps a better definition of how wide and deep alluvial rivers are going to be. This concept of "how big rivers are going to be" is at the basis of a definition for downstream hydraulic geometry. We are now looking at how the top width, mean flow depth, average flow velocity (and perhaps also slope) of a river will vary as a function of a flow discharge under bankfull conditions. We are going to compare smaller rivers and larger rivers to try to understand the changes in river morphology as we move in the downstream direction. This is quite interesting and a somewhat complex topic.

How do you define the bankfull discharge? What is the river width? What is the average depth? How does the flow velocity vary from small to large rivers? Does the slope depend solely on topography or also on the flow conditions? Nice questions. Without claiming to answer everything, the objective of this paper is to explore the downstream hydraulic geometry of alluvial rivers and try to answer some of these questions. A three-level approach is proposed here for the discussion of downstream hydraulic geometry: (1) empirical setting; (2) analytical developments; and (3) trade-offs and equivalences. 


\section{ALLUVIAL RIVERS}

\section{Bankfull conditions}

An example cross-section profile for the Matamek River is shown in Fig. 1. The downstream hydraulic geometry will define the top width, the average depth (obtained from the cross-section area divided but the top width), the mean flow velocity (obtained from the discharge divided by the cross-section area) and the energy slope of the river when the stage reaches bankfull conditions. Note that at any cross-section, there is only a single value of dominant discharge, channel width, mean flow depth and velocity and friction slope. Of course one would think that the bankfull flow discharge of the Grand Canyon of the Colorado River would be tremendously large. The concept of stability refers to sediment particles on the wetted perimeter that are coarse enough not to enter motion at the bankfull condition. If the sediment particles do not move at bankfull, the river geometry cannot depend on the flow conditions, e.g. Grand Canyon. The concept of equilibrium is therefore more appropriate to describe alluvial rivers and refers to the case where there is sediment transport under bankfull conditions, and equilibrium when an alluvial river bed is neither aggrading nor degrading through time (Julien 2002). This implies that the amount of sediment entering a river reach equals the amount of sediment leaving the same reach.

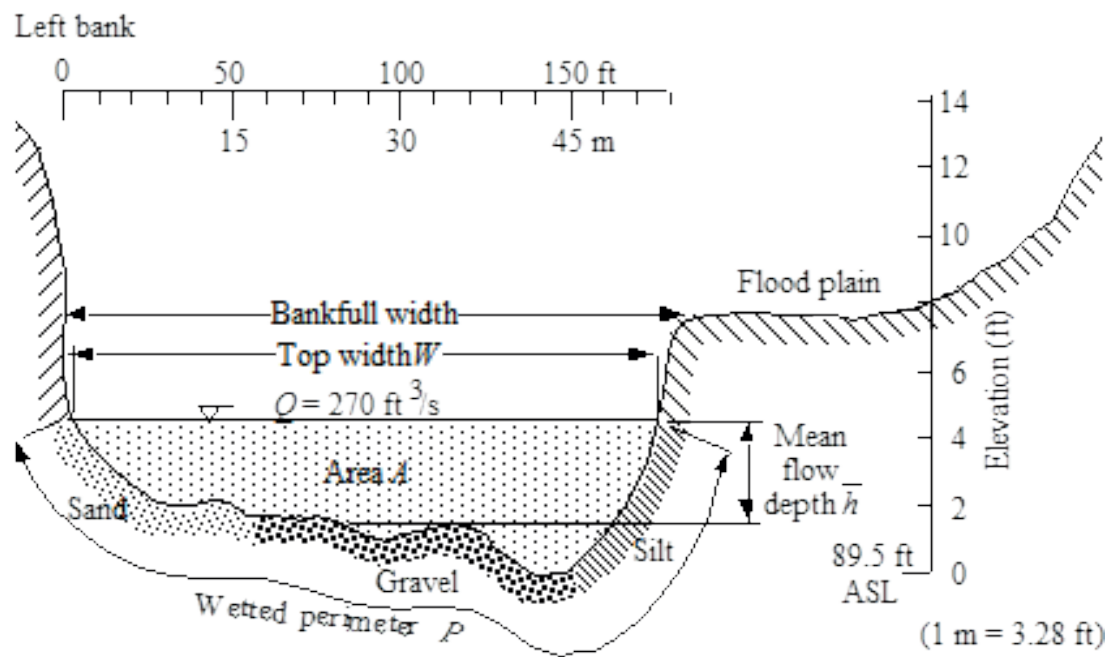

Fig. 1 Example of cross-section geometry from Julien (2002).

A bankfull discharge is determined by the discharge that a channel can convey when reaching the floodplain level. Natural levees result from the deposition of coarser fractions of the suspended load on the floodplain adjacent to the channel. The bankfull discharge would then be at the crest of the natural levees. The frequency of bankfull flows is not as clearly defined as it could be and it is still an active area of research. Perhaps the main concept is that riverbank vegetation increases roughness and stabilizes the banks. When vegetation is not given the chance to grow due to frequent mobilization of the bed sediment, possibly with sand/gravel bars, then the main channel will flow at a certain width called the non-vegetated channel width. Return periods of 1.5 and 2 years are most often encountered in the literature, but mean annual floods, mean annual flows, and 5-year floods have also been cited to describe the bankfull discharge of alluvial rivers - a good reference is Williams (1978).

\section{Regime equations}

Rivers have been observed for a long time and some of the earlier findings in downstream hydraulic geometry were motivated by the need to design appropriate irrigation canals without having dredging and maintenance problems. The construction of irrigation canals in India and Pakistan fostered investigations of the design of canals under "poised" conditions, i.e. a canal that is non-silting and non-scouring. Empirical relationships were proposed by Kennedy (1895), Lacey 
(1929) and Blench (1969), among others. The key relationships from Lacey are:

$$
\begin{aligned}
& V=0.794 Q^{1 / 6} f_{l}^{1 / 3}, \\
& R=0.47 Q^{1 / 3} f_{l}^{-1 / 3}, \\
& A=1.26 Q^{5 / 6} f_{l}^{-1 / 3}, \\
& P=2.66 Q^{1 / 2}, \\
& S=0.00053 f_{l}^{5 / 3} Q^{-1 / 6} .
\end{aligned}
$$

with the mean flow velocity $V$ in feet per second, the hydraulic radius $R_{h}$ in feet, the cross-section area $A$ in square feet, the wetted perimeter $P$ in feet, and the dimensionless slope as a function of the design discharge $Q$ in cubic feet per second, and the Lacey silt factor $f_{l}$. The Lacey silt factor $f_{l}$ was shown to increase with grain size as $f_{l}=1.59 d_{s}^{0.5}$.

In wide, shallow channels, the hydraulic radius is approximately equal to the flow depth, and the channel width can often be approximated by the wetted perimeter. The width-depth ratio thus increases slightly with discharge and decreases slightly with grain size. Another characteristic of the regime equation is that once the discharge and grain size are determined, a unique value of bed slope is calculated from equation (5). Note that the method does not allow changes in slope at a given discharge and grain size. Consequently, the velocity in equation (1) does not depend on slope. It is also interesting to note that the flow velocity is essentially constant, i.e. 1/6th power of both discharge and grain size. Finally, the width/depth ratio becomes essentially 7 times the mean flow velocity in $\mathrm{ft} / \mathrm{s}$. This is quite interesting that a velocity of $4 \mathrm{ft} / \mathrm{s}$ would result in a width/depth ratio $\sim 28$. Of course irrigation canals will tend to have lower width/depth ratios than natural rivers in order to minimize excavation costs. Perhaps the golden rule from the regime theory is that the channel width (or wetted perimeter $P$ in equation (4)) varies with the square root of discharge, and nothing else. Discharge thus controls channel width.

Leopold and Maddock (1953) also presented a set of power relationships between flow discharge and width, depth, velocity and slope of rivers. These empirical equations yielded similar exponents, but did not indicate any relationship with grain size or slope. The importance of grain size re-emerged in the 1980s with the contributions by Blench, Bray, Kellerhals, Hey, Thorne, Griffiths, Smart, and others. They showed that the grain diameter affected the downstream hydraulic geometry of gravel-bed rivers.

\section{THEORETICAL DEVELOPMENTS}

\section{Basic relationships for alluvial rivers}

The downstream hydraulic geometry of non-cohesive alluvial channels can be analytically determined (e.g. Julien 1988) from the following four relationships.

First, under steady-uniform bankfull flow conditions, the dominant discharge $Q$ is:

$$
Q=W h V,
$$

where the mean velocity vector $V$ is taken normal to the cross-sectional area, $h$ is the flow depth, and $W$ is the bankfull width. For channels with large width-depth ratios, the hydraulic radius $R_{h}=$ $A / P$ becomes equal to the mean flow depth $h$.

Second, the power form of the resistance equation is:

$$
V=a \sqrt{g}\left(\frac{h}{d_{s}}\right)^{m} h^{1 / 2} S^{1 / 2}
$$

where $g$ is the gravitational acceleration, $d_{s}$ the grain diameter, $S$ is the slope, and the exponent $m=$ $1 / \ln \left(12.2 \mathrm{~h} / \mathrm{d}_{\mathrm{s}}\right)$. Note, the value of $m=1 / 6$ corresponds to the Manning-Strickler resistance equation.

Third, the rate of sediment transport in alluvial channels is linked to the relative magnitude of the downstream shear force and the weight of the particle. The ratio of these two forces defines the Shields parameter $\tau *$ as: 


$$
\tau_{*}=\frac{h S}{(G-1) d_{s}},
$$

where $G$ is the specific gravity of sediment particles. The critical value of the Shields parameter $\tau_{* \mathrm{c}}$ $\approx 0.047$ identifies the beginning of motion of non-cohesive particles in turbulent flows over rough boundaries. In mobile-bed alluvial rivers, $\tau_{*}>\tau_{* c}$, the rate of sediment transport increases with the Shields parameter.

Fourth, for flow in bends with a radius of curvature $R$ proportional to the channel width $W$, the angle $\lambda$ between the transversal and downstream shear stress components is given by

$$
\tan \lambda=b_{r}\left(\frac{h}{d_{s}}\right)^{2 m} \frac{h}{W},
$$

where the value of $b_{r}=\left[\left(a^{2} W\right) /\left(\Omega_{R} R\right)\right]$ is assumed to be constant.

Equations (6)-(9) contain 13 variables, namely $W, h, V, S, Q, d_{s}, \tau *$, tan $\lambda, g, a, b r, G$ and $m$. Four relationships enable the selection of four dependent variables, $W, h, V$ and $\tau *$, as a function of the others. Julien (1988) showed that $Q, d_{s}$ and $\underline{S}$ were the primary independent variables. The variability in the other parameters is considered to be relatively small. When raised to powers less than 1 , these low variability parameters could be considered nearly constant.

\section{Julien-Wargadalam equations}

Julien and Wargadalam (1995) tested Julien's (1988) set of equations with a large data set including bankfull field measurements from 835 rivers and canals. For the practical applications, Manning's resistance equation was considered acceptable, i.e. $m=1 / 6$, and the downstream hydraulic-geometry relationships (also called the J-W equations) could simplify to

$$
\begin{aligned}
& h \cong 0.2 Q^{0.33} d_{50}^{0.17} S^{-0.17}, \\
& W \cong 1.33 Q^{0.44} d_{50}^{-0.11} S^{-0.22}, \\
& V \cong 3.76 Q^{0.22} d_{50}^{-0.05} S^{0.39}, \\
& \tau_{*} \cong 0.121 Q^{0.33} d_{50}^{-0.83} S^{0.83} .
\end{aligned}
$$

where $Q$ is the bankfull discharge in cubic metres per second, $d_{50}$ is the median grain diameter of the bed material in metres, and $S$ is the channel slope. The exponents of these equations were theoretically derived but the coefficients are empirical. Later, Lee and Julien (2006) obtained very similar results from regression of both the coefficients and exponents. Equations (10-13) conform to the geomorphic concept that rivers should form on any surface slope, with any sediment size small enough to be mobile under any given flow discharge.

The channel width varies primarily with discharge, like the regime equations. The power of grain size for the flow depth is also very close to the value predicted by the regime equations. The grain size affects primarily sediment transport via the Shields parameter. One of the main differences with the regime equations is that the flow velocity does depend on slope.

When using the simple unit bed-sediment discharge $q_{s} \cong 18 \sqrt{g d_{50}^{3} \tau_{*}^{2}}$ in $\mathrm{m}^{2} / \mathrm{s}$ from Julien (2002), the bed-material discharge $Q_{s}=W q_{s}$ resulted in the following relationship $Q_{s} d_{50}^{0.28} \sim Q^{1.11} S^{1.44}$ where $Q_{s}$ is the bed-material load in $\mathrm{m}^{3} / \mathrm{s}$. This relationship is amazingly similar to the downstream geometry relationship $Q S \sim Q_{s} d_{s}$ proposed by Lane (1955).

\section{EQUIVALENT CHANNEL WIDTHS}

This section presents relatively new concepts in the analysis of downstream hydraulic geometry of alluvial channels. This concept emerges from the field evidence that while the theoretical developments assume a state of equilibrium that is probably true on a long-term basis, the practical 
field conditions show that many rivers are in a perpetual state of flux and constantly adapt to recent floods and changing sediment loads.

\section{Sediment transport capacity changes with channel width}

Park (2013) recently analysed the sediment transport capacity relationship with both channel width and width/depth ratio. For the above mentioned sediment transport approximation, the maximum sediment transport capacity can be analytically obtained, and gives an optimum channel width of $130 \mathrm{ft}$ (as shown in Fig. 2; $39.6 \mathrm{~m}$ ).

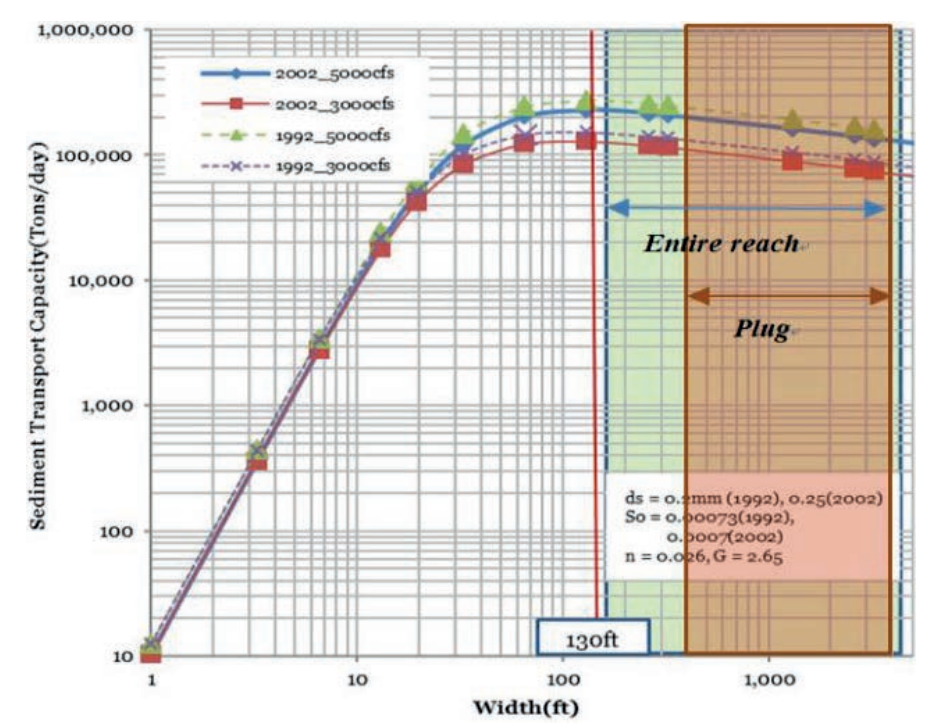

Fig. 2 Sediment transport capacity $v s$ channel width of the Rio Grande from Park (2013).

With this sediment transport relationship, the maximum was also found to occur at a width/depth ratio of 18 . It is important to note that different values of the optimum channel width and optimum width/depth ratios are obtained with different sediment transport equations. For instance, when using Yang's sediment transport formula, Park obtained an optimum channel width of $31 \mathrm{ft}(9.45 \mathrm{~m})$ and a very low width/depth ratio around 2. Similar graphs have been known for some time, but the new understanding from the analytical derivations is that for rivers narrower than the optimum channel width, the reason the transport capacity decreases is due to the differences between the flow depth and hydraulic radius. For most practical applications, river widths are usually larger than the optimum width, and the sediment transport capacity decreases with channel width. This also implies that in order to maintain a similar sediment transport rate, wider river reaches will require steeper slopes. This concept will be expanded upon shortly.

Park (2013) recently examined the formation of sediment plugs in the Rio Grande. Three sediment plugs formed in the Tiffany area of the Rio Grande in 1991, 1995 and 2005. In 2008, a new plug formed at a new location in the Bosque del Apache National Wildlife Refuge. Several factors were identified in plug formation including a long-term aggradation trend. The effects of channel width, overbank flows and natural levees with perching were part of a broader river avulsion process. Plugs tend to form rapidly when overbank flows are frequent, and when the Rouse number is fairly high (Ro $>\sim 1.2$ ). The location of sediment plugs has been attributed to local backwater effects from bridges and very sharp river bends.

\section{Channel width adjustments below dams}

The case of gradual change towards equilibrium has been investigated for the Rio Grande below Cochiti Dam under controlled flow and sediment conditions Richard et al. (2005a, b). Over the last 100 years, the channel width decreased considerable as pictured in Fig. 3.

The analysis assumed that the rate of change in channel width is proportional to the deviation from the equilibrium channel width. This hypothesis has been first tested on the Rio Grande as 


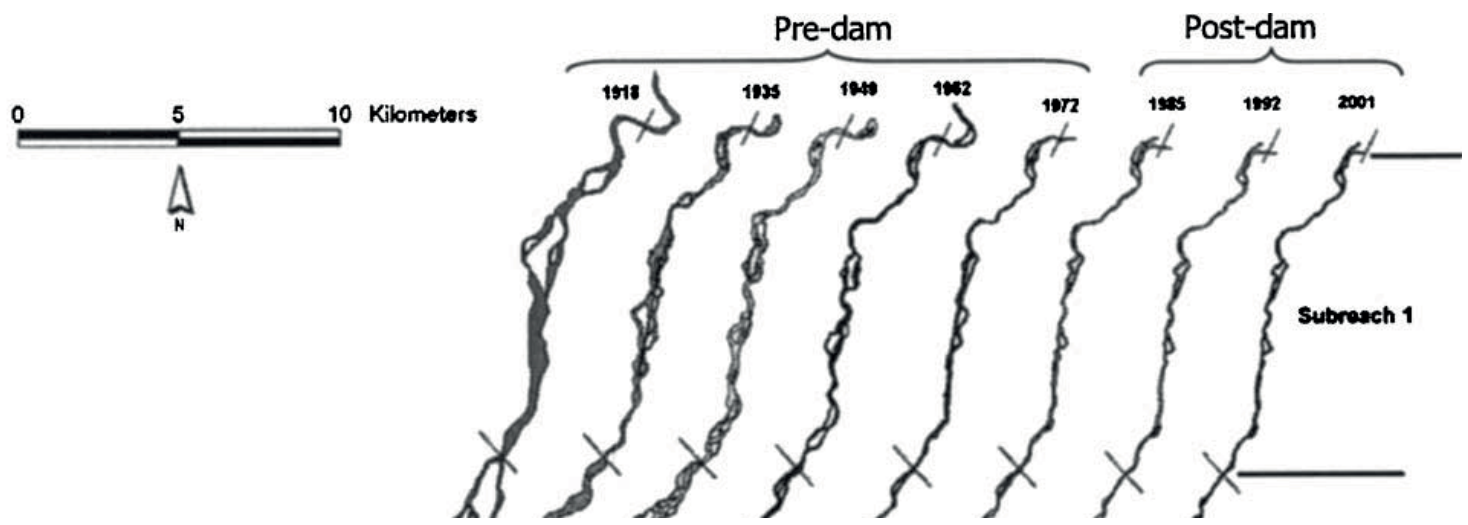

Fig. 3 Changes in channel morphology of the Rio Grande below Cochiti Dam from 1918-2001 from Richard et al. $(2005 \mathrm{a}, \mathrm{b})$.

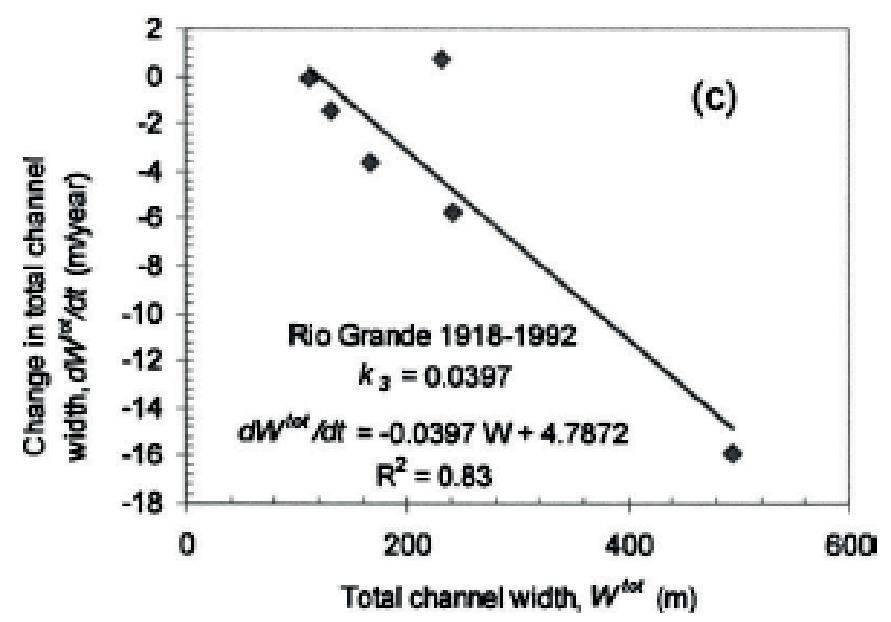

Fig. 4 Hypothesis that the change in channel width is proportional to the deviation from equilibrium from Richard et al. (2005a).

shown in Fig. 4. The hypothesis has also been tested on several other rivers including the Jemez River, Wolf Creek and the Arkansas River by Richard et al. (2005a) and also on the Hwang River below Hapcheon dam by Shin and Julien (2010).

Accordingly, the channel width is a decreasing exponential function of time:

$$
W(t)=W_{e}+\left(W_{o}-W_{e}\right) e^{-k t} .
$$

where $W_{o}$ is the original channel width and $W_{e}$ is the equilibrium channel width $W_{e}$ from the J-W equation, and time $t$ is in years. The values of the coefficient $k$ remained fairly comparable for all these rivers and varied from 0.02-0.11. An example for the Rio Grande is shown in Fig. 5.

Shin and Julien (2011) also defined the gradual morphological changes of the Hwang River due to daily flow pulses from peak hydropower production. It was found that sediment transport rates due to the daily pulses increased sediment transport by approximately $30 \%$. This accelerated the rate of bed degradation and armoring below Hapcheon Dam. The morphological changes in this case were primarily a significant decrease in channel width, significant riverbed coarsening and armoring with bed material sizes changing from $0.2 \mathrm{~mm}$ sand to $20-30 \mathrm{~mm}$ gravels.

\section{Equivalent channel widths}

Leon et al. (2009) recently developed the concept of equivalent channel widths. This is a very important new concept in the analysis of downstream hydraulic geometry of alluvial rivers. Since the width/depth ratio of alluvial channels is a very weak parameter in the analysis of downstream hydraulic geometry, river equilibrium is possible for a wide range of width/depth ratios. This implies that secondary adjustments to channel depths and slope are possible once the channel 


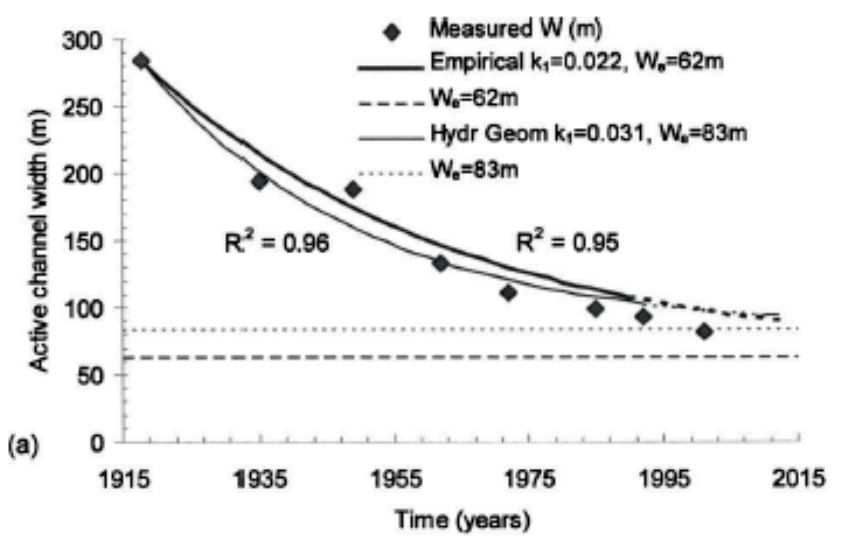

Fig. 5 Gradual changes in channel width below Cochiti dam from Richard et al. (2005a)

width has been determined. From a detailed analysis of the effects of channel width changes on sediment transport and on slope, Leon et al. (2009) found that wider channels will require steeper gradients to convey the same sediment load. For wide channels, the slope-width relationship is approximately $S_{r} \sim W_{r}^{1 / 7}$. This could be tested on the Rio Grande where successive river reaches alternated between a channel width of $\sim 50 \mathrm{~m}$ and $\sim 250 \mathrm{~m}$. This five-fold change in channel width over an extended period of time was sufficient to significantly increase the slope in the wider reaches in a way that could be measured with accurate field measurements at numerous crosssections as shown in Fig. 6.

Some of the new achievements in the analysis of the gradual changes in channel slope over time have been on the Rio Grande where numerical simulations, including daily variability in flow discharge and sediment load, have shown that the channel slope also adjusts to new equilibrium conditions in a decreasing exponential form. For instance numerical simulations from Leon et al. (2009) in Fig. 7 show the gradual changes in channel slopes induced from the channel width changes.

The numerical results in the slope adjustments of Fig. 7 can be approximated with a decreasing exponential reminiscent of equation (14) in which the channel width has been replaced with the channel slope as:

$$
S(t)=S_{e}+\left(S_{o}-S_{e}\right) e^{-k t} .
$$

where $S_{o}$ is the original channel slope and $S_{e}$ is the equilibrium channel slope from the relationship between width and slope for wide rivers, e.g. $S_{r} \sim W_{r}^{1 / 7}$, and time $t$ is in years.

\section{Time scale for hydraulic geometry adjustments}

A time scale for the slope adjustment can be determined from the coefficient $k$. Since the changes in channel width and slope become asymptotic, the equilibrium width or slope may mathematically never be achieved. In practice, it is also becoming possible to quantify the time scale for a certain level of adjustment $p$ from the following formula:

$$
T_{p}=\frac{-1}{k} \ln (1-0.01 p) \text {. }
$$

where $k$ is the coefficient of the exponential relationship and $p$ is the adjustment percentage. Consequently, $90 \%$ of the slope adjustment $(p=90)$ will take place in $T_{90}=2.3 / k$, and half the adjustment will take place in $T_{50}=0.7 / k$. For instance, on the Rio Grande with $k=0.10$ per year, the half-life of the slope adjustment will be about 7 years and $90 \%$ of the adjustment will take place in $\sim 23$ years. As expected, the slope adjustment of rivers does take a long time.

\section{Restoring river equilibrium}

Some studies also focus on the restoration of river equilibrium after natural and anthropogenic effects. For instance, the case of sediment accumulation behind estuary barrages (low head dams 

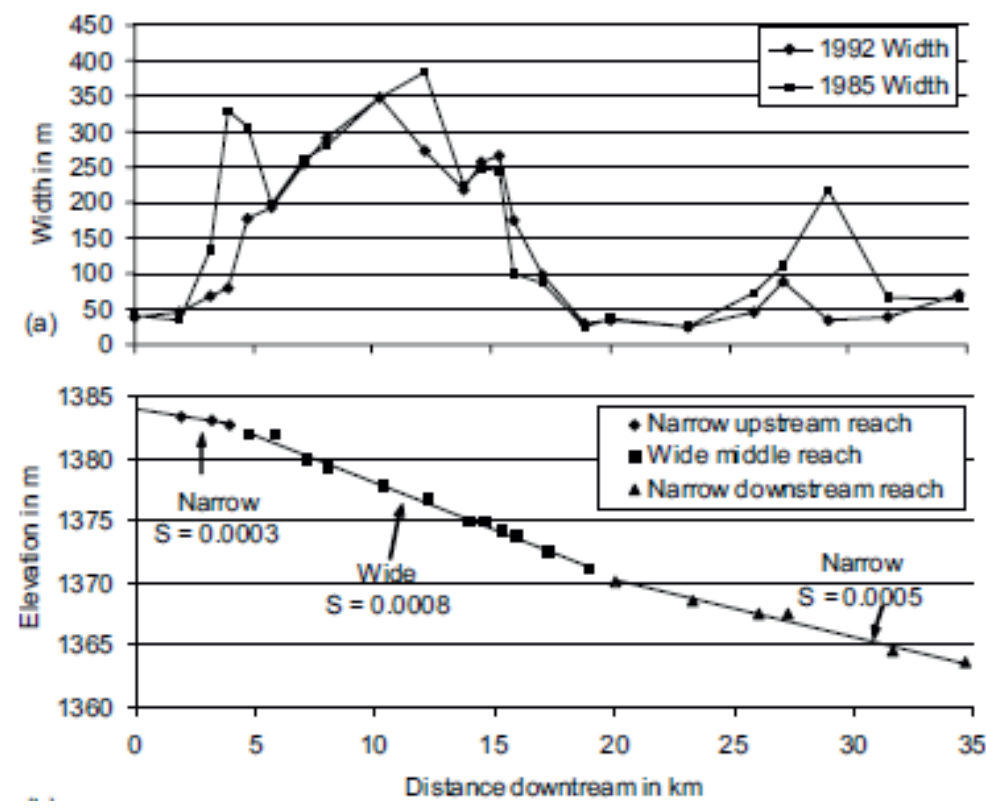

Fig. 6 Changes in channel slope as a result of channel width changes on the Rio Grande (Leon et al., 2009).
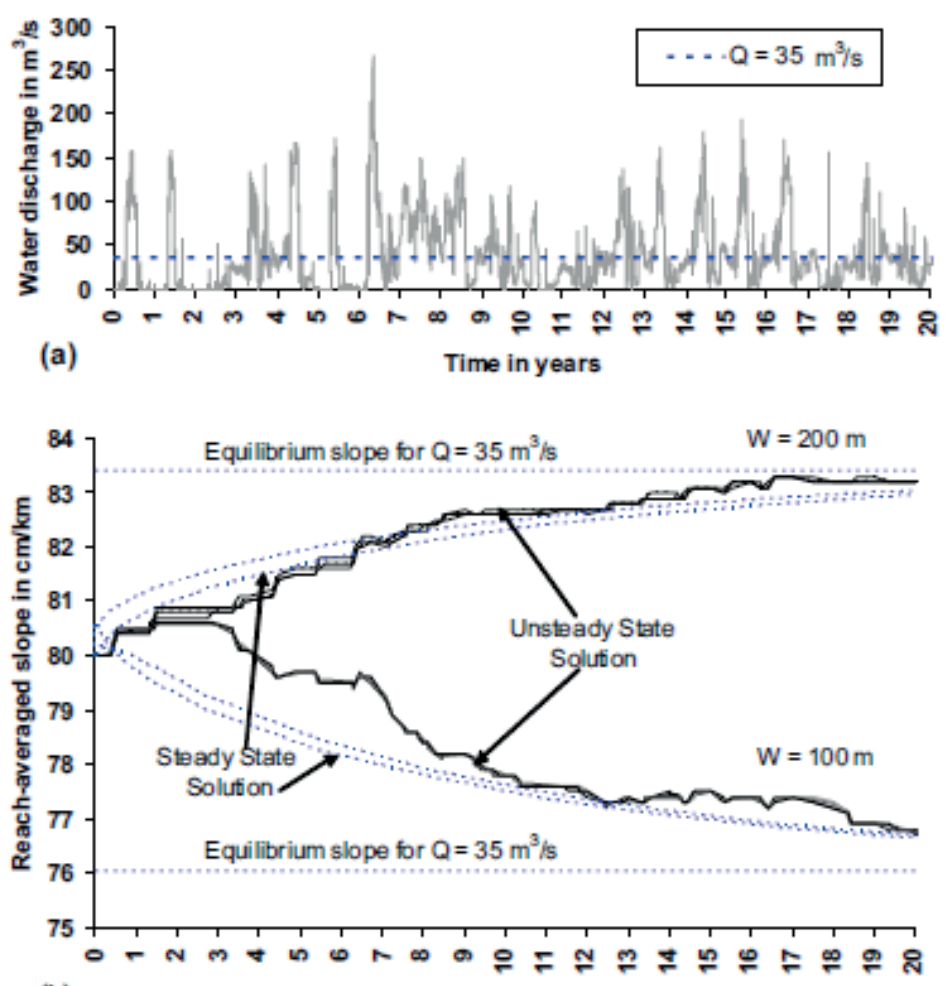

(b)

Time in years

Fig. 7 Channel slope changes as a result of channel width changes on the Rio Grande from Leon et al. (2009).

to prevent salt-water intrusion in river estuaries) has been investigated by Ji et al. (2011). Of course, sediment accumulation upstream of the barrages can be removed mechanically with cutterhead dredges, but this can be a somewhat expensive maintenance approach. Alternative use of changes in the daily operations of the water levels at the barrage can naturally flush most of the sediment while maintaining a state of equilibrium in the fluvial system.

Another case of river restoration on the Rio Grande has been discussed by Richard and Julien 
(2003) and Julien et al. (2005) for the opposite situation where the sediment supply of a river downstream of a dam was essentially eliminated after dam construction.

\section{CONCLUSIONS}

Alluvial rivers are quite fascinating and efficient irrigation canals have been successfully designed based on pre-computer empirical formulas like the regime equations. Analytical derivations have been available for a couple decades and the results are in reasonable agreement with field observations and regime equations. Recent advances focus on the ever adapting capabilities of rivers in face of changing water flows and sediment loads. The changes in downstream hydraulic geometry below dams are well-documented and lead to understanding that rivers adjust their geometry in a decreasing exponential fashion. The half-life of the adjustment can span over several years such that rivers may be in a perpetual state of re-adjustment in seeking a new state of equilibrium. Unique values of channel width, depth, velocity and Shields parameter may not be possible even for fixed values of discharge, grain size and slope. Finally, the new concept of equivalent channel width is important to understand the trade-offs between channel width and slope that are possible in alluvial channels.

Acknowledgements The author is particularly grateful to Dr D.C. Baird, R. Padilla and J. Aubuchon at the US Bureau of Reclamation for their collaboration on numerous studies of the Rio Grande. Nevertheless, this paper does not reflect the opinions and policies of Reclamation. Advances in understanding downstream hydraulic geometry have been possible through the successful contributions of $\mathrm{PhD}$ dissertation research by Drs Claudia Leon, Gigi Richard, Un Ji, Youngho Shin, Seema Shah-Fairbank, Kiyoung Park and others at Colorado State University. The detailed data analyses and carefully prepared reach reports have been extremely instrumental to reach this new level of understanding of alluvial rivers. The contributions of J. Rainwater, T. Owen, T. Bender, C. Shrimpton, A. Larsen, F. Jay, S. Novak, A. Paris, C. Anderson, M. Remillard, C. Vensel, M. Sixta, and J. Albert, with the hope not to forget anyone, have been really appreciated.

\section{REFERENCES}

Blench, T. (1969) Mobile-Bed Fluviology. Univ. of Alberta Press, Edmonton, Canada.

Ji, U., Julien, P.Y. and Park, S.K. (2011) Case-study: Sediment flushing and dredging near the Nakdong River Estuary Barrage, J. Hydraulic Eng., ASCE 137(11), 1522-1535.

Julien, P. Y. (1988) Downstream hydraulic geometry of noncohesive alluvial channels. Proc. Intl Conf. on River Regime, Wiley, New York, 9-16.

Julien, P.Y. (2002) River Mechanics. Cambridge University Press, 434p.

Julien, P. Y. and J. Wargadalam (1995) Alluvial channel geometry: theory and applications. J. Hydraul. Eng., ASCE 121, 312-325.

Julien, P.Y., Richard, G. and Albert, J. (2005) Stream restoration and environmental river mechanics. Special Issue of the $J$. River Basin Management 3(3), 191-202.

Kennedy, R. G. (1895) The prevention of silting in irrigation canals. Minutes of Proc. Inst. Civ. Eng. London 119, 281-290.

Lacey, G., (1929-30) Stable channels in alluvium. Minutes Proc. Inst. Civ. Eng. London, 229, 259-292.

Lane, E. W. (1955) The importance of fluvial geomorphology in hydraulic engineering. Proc. ASCE 81, 1-17.

Lee, J.S. and Julien, P.Y. (2006) Downstream hydraulic geometry of alluvial channels. J. Hydraul. Eng., ASCE132(12), 1347-1352.

Leon, C., Julien, P.Y. and Baird, D.C. (2009) Case study: equivalent widths of the Middle Rio Grande, New Mexico. $J$. Hydraulic Eng., ASCE 135(4), 306-315.

Leopold, L.B. and Maddock, T. Jr (1953) The Hydraulic Geometry of Stream Channels and some Physiographic Implications USGS Prof. Paper 252, U.S. Govt Printing Office, Washington, DC.

Park, K. (2013) Mechanics of sediment plug formation in the Middle Rio Grande, New Mexico. PhD dissertation, Department of Civil and Environmental Engineering, Colorado State University, Fort Collins, Colorado, USA, 199p.

Richard, G.A. and Julien, P.Y. (2003) Dam impacts and restoration on an alluvial river - Rio Grande, New Mexico. Int. J. Sediment Research 18(2), 89-96.

Richard, G.A., Julien, P.Y. and Baird, D.C. (2005a), Case study: modeling the lateral mobility of the Rio Grande below Cochiti Dam, New Mexico. J. Hydraulic Eng., ASCE 131(11), 931-941.

Richard, G.A., Julien, P.Y. and Baird, D.C. (2005b) Statistical analysis of lateral migration of the Rio Grande. Special Issue of Geomorphology 71, 139-155.

Shin, Y.H. and Julien, P.Y. (2010) Changes in hydraulic geometry of the Hwang River below the Hapcheon Re-regulation Dam, South Korea. Int. J. River Basin Management 8(2), 139-150.

Shin, Y.H. and Julien, P.Y. (2011) Case-study: effect of flow pulses on degradation downstream of Hapcheon Dam, South Korea. J. Hydraulic Eng., ASCE 137(1), 100-111.

Williams, G. P. (1978) Bank-full discharge of rivers. Water Resources Res. 14, 1141-1154. 